\title{
The Real-Time Research of Optimal Power Flow Calculation in Reduce Active Power Loss Aspects of Power Grid
}

\author{
Yuting $\operatorname{Pan}^{1}$ \\ College of Electronic and Electrical Engineering \\ Shanghai University of Engineering Science \\ Songjiang District, Shanghai 201620, China
}

\author{
Zhiqiang Yuan ${ }^{3}$ \\ Shanghai Electric Power Design Institute Co., Ltd. \\ Huangpu District, Shanghai 200025, China
}

\author{
Yuchen Chen $^{2}$ \\ College of Electronic and Electrical Engineering \\ Shanghai University of Engineering Science \\ Songjiang District, Shanghai 201620, China
}

\author{
Bo Liu ${ }^{4}$ \\ Shanghai Electric Power Design Institute Co., Ltd. \\ Huangpu District, Shanghai 200025, China
}

\begin{abstract}
In order to research how to availably reduce the active power loss value in power grid system when the power system is operating, it offers a quantitative research in theory through conceiving the unbalanced losses of power grid system under the overloading bus as the investigative object, and establishing an active power loss mathematical model. It carries out online real-time optimal flow calculation within the condition that meets the control variables and state variables of the equality and inequality constraints. For some branches with larger network loss, it respectively adopts three methods, including voltage regulation method, reactive power compensation method, changing the branch's cross-sectional area method, to reduce the general active power loss values. Moreover, it compares the compensation equivalent of three methods during the recovery process of the general active power loss in the power grid. Taking IEEE14 as an example, it verifies the effectiveness of the proposed methods. It not only can offer a reasonable measure to reduce the losses of power grid, but can provide some reliable reference for the power grid dispatching personnel.
\end{abstract}

Keywords-optimal power flow; voltage regulation; reactive power compensation; cross-sectional area; active power loss

\section{INTRODUCTION}

In recent years, with the increasement of electricity power c onsumption, the scale of the power grid has been enlarged year by year, the power loss in the electricity power system is becoming a more and more serious problem, the research of how to reduce the active power loss not only be comes the major factor of reducing the cost of electricity power system, but also becomes the research direction of the future's electrical power supply.

Wide Area Measurement System (WAMS) technology, which has a main characteristic of collecting data in distributed, has been widely concerned. The main principle of WAMS technology is: real-time acquisition of voltage, phase data and relative information from Phasor Measurement Unit (PMU) in different grid, comparing with a synchronously upload to the computer, therefore monitoring and controlling the overall loss of power system [1-4]. Calculating the active power loss by computer power flow to realize the real time measurement of power grid, there are generally 3 basic steps: (1) Establishing mathematical model of the problem; (2) Using an efficient analysis method; (3) The preparation of the relevant software program [5-8].

This article mainly studies on how to find the combined me asure to decrease the active power loss in the power grid. It sets up the mathematical model of the active power loss, and uses the independently developed online realtime optimal Newton-

Raphson power flow calculation software to calculate cases.

This article adopts three decreasing network loss methods, including voltage regulation method, reactive power compensation method, changing the branch's cross-sectional area method, to start power flow calculation for the IEEE 14bus system and analyze the compensation equivalent of three methods. It can offer a reliable basis for power grid dispatching personnel to adopt a more effective way so as to decrease the power loss in the condition of the load overload.

\section{A MATHEMATICAL MODEl OF POWER GRID OPTIMAL FLOW CALCULATION}

\section{A. The objective function of optimal power active power loss of power network}

The intelligent vacuum circuit breaker online monitoring system is composed by the host computer, the lower computer and signal processing modules. The lower computer hardware platform consists of a TMS320F2812 DSP and peripheral hardware circuits. It collects mechanical parameters, divideshut brake circuit current signal and vibration signal of vacuum circuit breaker. The host computer uses ARM as a core, mainly working as remote communication with the host computer, and getting the results of data processing and eigenvalues from the DSP at the same time. The preprocessed data is transferred from DSP to ARM via an HPI interface, and transmitted via the Ethernet interface to the host computer for data analysis 
and processing, so as to determine the current status of the circuit breaker, and analyze its operation situation and diagnose malfunctions. The system structure is shown as Fig.1.

Through the analysis of regression loss mathematical model that can improve accuracy of network loss in the calculation of load variation which presented in the literature 6 , in the case of consulting a lot of related information, successfully developing a kind of power network active power loss mathematical model which is suitable for online realtime power flow calculation, the objective function constructed as shown in equation (1):

$$
\min f(x)=\min \sum_{i, j \in l}\left(\Delta P_{j i}+\Delta P_{i j}\right)
$$

In the formula, $\Delta P_{j i}$ is the active power loss value from the $j$ node flow to the $i$ node, $\Delta P_{i j}$ is the active power loss value from the $i$ node flow to the $j$ node.

\section{B. The system constraints of optimal power flow [9]}

The active power loss objective function (1) should satisfy the constraints shown in formula (2), the constraint condition in the common constraint is introduced in the line flow constraints, in order to reasonably control the reactive power load distribution.

$$
\left\{\begin{array}{l}
P_{G i}-P_{L i}-e_{i} \sum_{j=1}^{n}\left(G_{i j} e_{j}-B_{i j} f_{j}\right)-f_{j} \sum_{j=1}^{n}\left(G_{i j} f_{j}-B_{i j} e_{j}\right)=0 \\
Q_{G i}-Q_{L i}-f_{i} \sum_{j=1}^{n}\left(G_{i j} e_{j}-B_{i j} f_{j}\right)-e_{j} \sum_{j=1}^{n}\left(G_{i j} f_{j}-B_{i j} e_{j}\right)=0 \\
S_{i j}^{2}=P_{i j}^{2}+Q_{i j}^{2} \leq S_{i j \max }^{2} \quad i, j=1,2, \ldots, n \\
V_{i \min } \leq V_{i} \leq V_{i \max } \\
P_{G i \min } \leq P_{G i} \leq P_{G i \max } \quad i=1,2, \ldots, n_{g} \\
Q_{G i \min } \leq Q_{G i} \leq Q_{G i \max } \quad i=1,2, \ldots, n_{g}
\end{array}\right.
$$

In the type, $P_{G i}$ and $Q_{G i}$ are the active power and reactive power output of generator $i$ respectively; $P_{L i}$ and $Q_{L i}$ are the active power and reactive power load of generator $i$ respectively; $e_{i}$ and $f_{i}$ are the real part and imaginary part of the node voltage of $i$ respectively; $V_{i}$ is the voltage value for node $i ; G_{i j}$ and $B_{i j}$ are the conductance and the susceptance of the branch $i j ; n_{g}$ is the number of generator; $S_{i j}, P_{i j}$ and $Q_{i j}$ are the apparent power, active power and reactive power of the branch ij respectively.

\section{A CASE OF OPtIMAL POWER FLOW CALCULATION IN ACTIVE POWER LOSS}

The Fig.1 is a IEEE14 node grid, it consists of 20 branches, 14 nodes which contains 3 transformer branch and 17 transmission lines, in the 5 node of power plant, the $1 \#$ node is the balance node, the rest of the load nodes is the $P Q$ node, the power plant node is the $P V$ node。

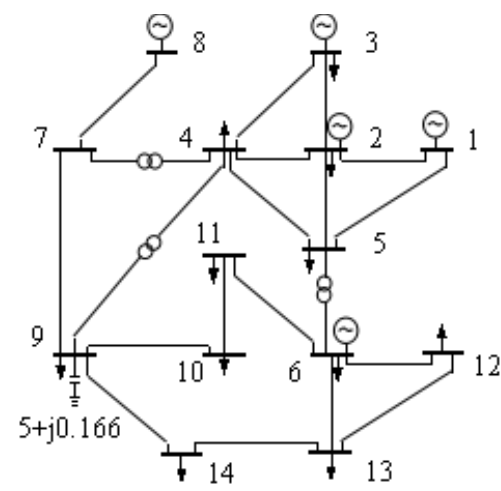

Fig. 1. IEEE14 typical grid topology

For verifying the loss compensation ability of the IEEE14 node power grid in the long distance transmission, this paper selects the No.9 bus which is the furthest node from all generators in the theory as the research object. Assuming the No.9 bus overloads, its load value is equal to 1.25 times the normal load conditions, that is, the load value is $0.36875+j 0.2075 \mathrm{MW}$, all the remaining data of IEEE14

\begin{tabular}{|c|c|c|c|}
\hline Name & $\begin{array}{c}\text { The load value of No. } \\
9 \text { bus/MW }\end{array}$ & $\begin{array}{c}\text { The power loss } \\
\Delta P_{\text {Loss }}^{\prime} \text { /MW }\end{array}$ & $\begin{array}{c}\text { The variation of } \\
\text { network general active } \\
\text { power loss increment } \\
\text { value } \Delta P_{L O S S}^{\prime} / \mathrm{MW} \\
\end{array}$ \\
\hline $\begin{array}{l}\text { Initial } \\
\text { Value }\end{array}$ & $0.295+\mathrm{j} 0.166$ & 0.195477 & 0.008618 \\
\hline $\begin{array}{l}\text { Change } \\
\text { Value }\end{array}$ & $0.36875+\mathrm{j} 0.2075$ & 0.204095 & \\
\hline
\end{tabular}
node voltage are consistent with the normal conditions. Through the power flow calculation, we can know the before and after change of the general active power loss values of power network, specific data is indicated in TABLE I.

TABLE I. The UnChanging And Changing Load Value $\Delta P_{\text {Loss }}^{\prime}$ OF TOTAL GRID ACTIVE POWER Loss IN 9 BUS

As it can be seen from the TABLE I, after the load of No.9 bus has increased 1.25 times than before, the general active power loss increment value $\Delta P_{\text {Loss }}^{\prime}$ of network is $0.008618 \mathrm{MW}$.

By means of three kinds of methods, including voltage regulation, reactive power compensation, changing conductor cross-sectional area, it computes the general power active power loss variation in every methods by the online real-time power flow calculation software, then let them respectively compare with the value 0.008618. After that, it gets the corresponding comparative quantities $\Delta P_{L O S S} 1$ 、 $\Delta P_{\text {LOSS }} 2 、 \Delta P_{\text {LOSS }} 3$. The final analysis of compensation equivalent conditions among three kinds of methods will be given. 


\section{A. The regulation of No.2 bus voltage}

From the flow computational results, the branch 1-2 has the largest network loss. As we know, the No.1 bus is the balance of nodes, therefore it considers to regulate the voltage of No. 2 bus so as to effectively reduce the network loss. According to the data of the power grid, it analyzes the function relationship between $U_{2}$ and $\Delta P_{\text {LOSS }} 1$ :

$$
\Delta P_{\text {LOSS }} 1=9.6381165-17.9458 * U_{2}+8.355 * U_{2}^{2} .
$$

From Fig.2, it can be more intuitive to observe the corresponding changes.

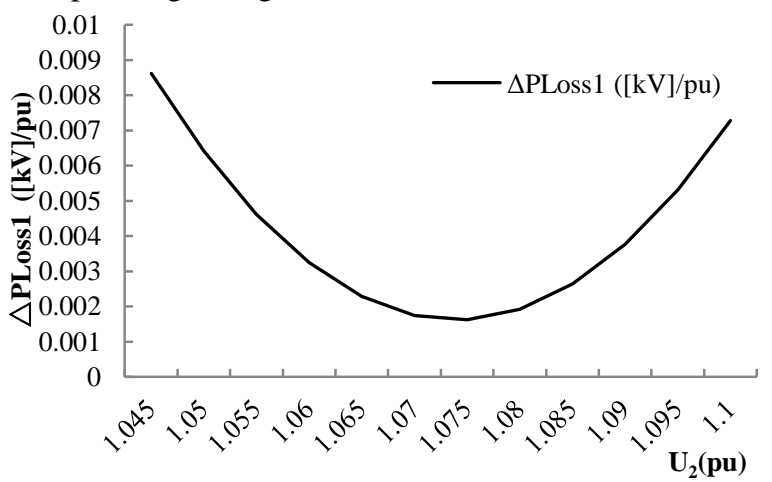

Fig. 2. The changing situation of $\Delta P_{\text {LOSS }} 1$ with elevating of the value in $U_{2}$

It can be seen from the Fig.2, with the value $U_{2}$ of No. 2 bus voltage is gradually increasing, the general active power loss comparison value $\Delta P_{\text {LOSS }} 1$ of power grid shows a decreased first and then increased trend, it can be in accordance with the advantages of reducing loss to adjust $U_{2}$ value, in order to achieve the best loss reduction effect.

\section{B. Reactive power compensation of No.4 and No.5 bus}

From the power flow calculation, we can know that the reactive power near 4 and No. 5 bus is lower, therefore we should use compensatory of result on the spot scheme to compensate reactive power for No.4 and No.5 bus, so that it can improve active power loss value of the whole grid to achieve the purpose of reducing network loss. Specific data is shown in the TABLE II.

TABLE II. THE VAlue of $\mathrm{D} P_{\text {LOSS }}{ }^{2}$ with COMPENSATING ${ }^{\mathrm{D}} Q_{C}$ IN NO.4、 NO.5 Bus

\begin{tabular}{ll}
\hline$\Delta Q_{c} /(p u)$ & $\mathrm{D} P_{\text {LOSS }} 2 /([M \mathrm{var}] / p u)$ \\
\hline 0 & 0.007990106 \\
0.15 & 0.006042856 \\
0.3 & 0.004570166 \\
0.45 & 0.003456381 \\
0.6 & 0.002614035 \\
0.75 & 0.001976975 \\
0.9 & 0.001495171 \\
1.05 & 0.001130786 \\
\hline
\end{tabular}

The TABLE II shows the reactive power compensation increment $\mathrm{D} Q_{c}$. It is the reactive power compensation value of No.4 and No.5 bus is the value that is compared with $0.008618 \mathrm{MW}$ after compensating for corresponding. According to the calculated data, it gets the function relationship:

$$
\mathrm{D} P_{\text {LOSS }} 2=0.007990106 * e^{-1.862181813 * \mathrm{~V} Q_{c}} .
$$

The corresponding situation can be seen more intuitively from the Fig.3.

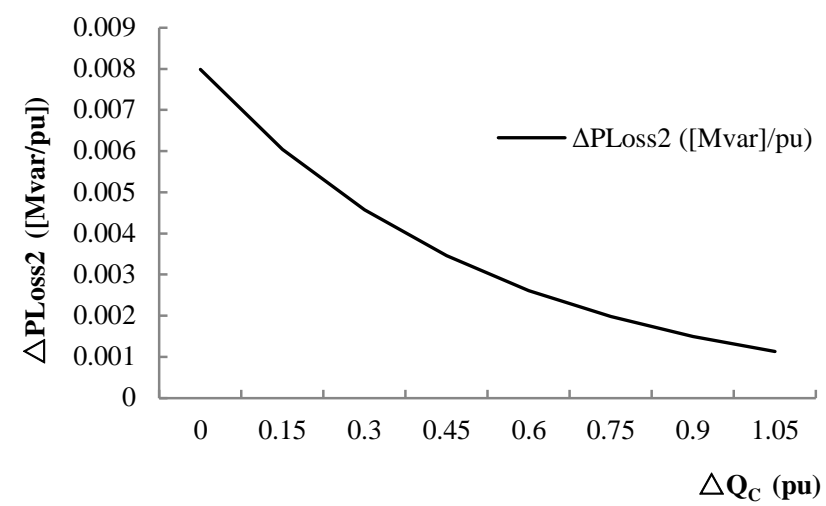

Fig. 3. The changing situation of $\mathrm{D} P_{\text {LOSS }} 2$ with compensating $\mathrm{D} Q_{C}$ in NO.4 、NO.5 bus

From the Fig.3, with the reactive power compensation increment $\mathrm{D} Q_{c} \quad$ increasing gradually, the compared value of network general active power loss increment value $\mathrm{D} P_{\text {Loss }} 2$ has shown a trend of decreasing.

\section{Changing the branch's cross-sectional area which the network loss is larger}

By the power flow calculation, the IEEE14 nodes with grid network loss of the top six branches in descending order in turn are as follows in TABLE III.

\section{TABLE III. THE NETWORK LOSS DESCENDING ORDER OF IEEE14 NODE} POWER GRID BRANCH

\begin{tabular}{llll} 
Initial node & $\begin{array}{c}\text { Termination } \\
\text { node }\end{array}$ & $\begin{array}{c}\text { Active power } \\
\text { loss }\end{array}$ & $\begin{array}{c}\text { The ranking } \\
\text { of net loss }\end{array}$ \\
\hline 1 & 2 & 0.090176 & 1 \\
1 & 5 & 0.035943 & 2 \\
2 & 3 & 0.026037 & 3 \\
3 & 4 & 0.019457 & 4 \\
2 & 4 & 0.012471 & 5 \\
2 & 5 & 0.006363 & 6 \\
\hline
\end{tabular}

Considering in this theoretical case, it changes the crosssectional area of different branches respectively, The corresponding grid changes of the general active network loss comparison value is shown in Fig.4. 


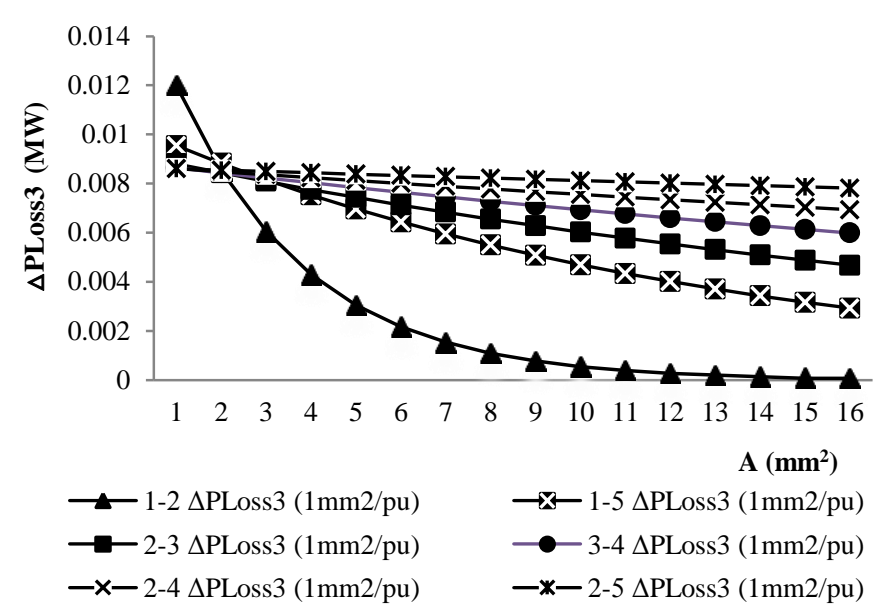

Fig. 4. The changing situation of $\mathrm{D} P_{\text {LOSS }} 3$ with $1 \mathrm{~mm}^{2}$ increment of crosssectional area values ranked the top six in power grid loss

The Fig.4 shows that with the increasing of branch crosssectional area value, and it all shows a trend of decreasing network loss. Among them, the loss reduction effect of branch 1-2 is most obvious, while the effect of branch 2-5 is the most unobvious one.

D. To compare compensation equivalent of the three methods Changing the branch's cross-sectional area which the network loss is larger

From the above analyses, we can conclude that each of three methods discussed can reduce the general active power loss in some degree. The effects of three methods in the view of loss reduction are compared in order to get compensation equivalent. The relationships among the three methods and the compared values of general active power loss are shown in Fig.5.

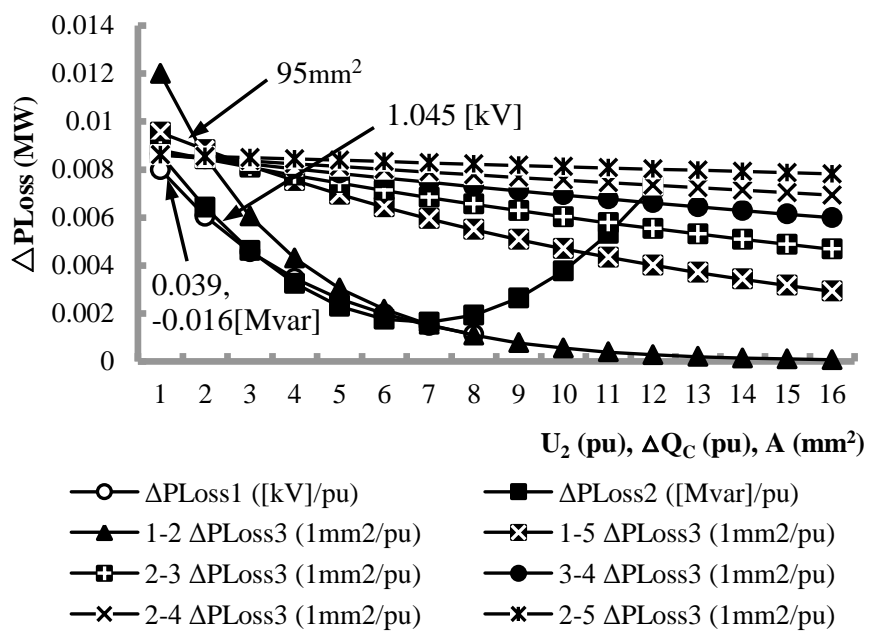

Fig. 5. The relationships among the three methods and the compared values of power grid loss

According to the Fig.5, the initial reactive power values of No.4 and No.5 bus are 0.039 [Mvar] and -0.016 [Mvar] in reactive power compensation method. The initial voltage of bus is $1.045[\mathrm{kV}]$ in voltage regulation method. The initial area value of each branch is $95 \mathrm{~mm}^{2}$ in changing the branch cross-sectional area method.

In TABLE IV, it shows compensation equivalent of each method when $\mathrm{D} P_{\text {Loss }}$ is reduced from $0.008 \mathrm{MW}$ to $0.006 \mathrm{MW}$.

TABLE IV. THE NETWORK LOSS DESCENDING ORDER OF IEEE14 NODE POWER GRID BRANCH

\begin{tabular}{ll}
\hline Name / (unit) & $\begin{array}{l}\text { Compensation } \\
\text { equivalent }\end{array}$ \\
\hline $\mathrm{D} U_{2} /(p u)$ & 0.005 \\
$\mathrm{D} Q_{C} /(p u)$ & 0.15 \\
$A(1-2) /\left(\mathrm{mm}^{2}\right)$ & 0.9
\end{tabular}

According to the principle that the increasing of the loss maximum branch cross-sectional area value of power grid can improve loss reduction effect better, the crosssectional area compensation equivalent in the TABLE IV just considers changing the cross-sectional area value of the branch 1-2. In the Fig.5, it lists the changing relationship between the top six branches of the power grid loss and the general power grid active power loss comparison values. Because of the actual situation of cross sectional area of the increment value can't be $1 \mathrm{~mm}^{2}$, if we consider the actual factors, it changes the cross-sectional area value of branch 2-5 will be obtained with a more reasonable compensation equivalent than the two method of voltage regulation and reactive power compensation.

\section{CONCLUSIONS}

This article uses the online software of optimal power flow calculation to calculate and analyze three methods' effect on the general active power loss of power network loss reduction in the condition of No.9 bus, which is the more distal bus to the generator in the network of IEEE 14 nodes, overloads. We can get three methods' compensation equivalent. The specific conclusions are as follows:

1) If the value of $U_{2}$ raises, the change trend of network general active power loss increment value $\mathrm{D} P_{\text {Loss }} 1$ is decreased first and then increased. When the value of $U_{2}$ is about $1.074[\mathrm{kV}]$, the effect of reducing the loss is the best.

2) The increasing of 0.15 unit in $Q_{C}$ corresponds to the increasing of 0.005 unit in $U_{2}$, which means that the way of voltage regulation is better than reactive power compensation in the effect of reducing the loss.

3) When it changes the value of cross-sectional area in different branches, the general active power loss comparison value $\mathrm{D} P_{\text {Loss }} 3$ shows a monotonic decreasing trend. Also, it has a more obvious effect in reducing the loss if it raises cross-sectional area value of the branch which has a larger network loss.

4) Both reactive power compensation method and changing the branch's cross-sectional area method need to consider the additional expenses, so they are not economic in practical engineering application. Therefore, we should first consider it to drop network loss through voltage regulation 
method. When the per unit value of $U_{2}$ is up to $1.074[\mathrm{kV}]$, then we can take changing the branch cross-sectional area method in order to realize the aim of decreasing the network general active power loss effectively.

Through the study of different methods of reducing the network general active power loss, we can provide reliable information for the dispatchers. This is helpful to analyze how to reduce the actual power grid loss effectively. In the future, the research direction will be dedicated to the combination of synchronous phasor measurement unit and the present research, to realize the purpose of on-line measurement of the network loss among different power grid, thus it can provide more useful information for the power grid and relevant departments.

\section{ACKNOWLEDGMENT}

The project has been supported by Chinese National Natural Science Foundation (No.51177099), Shanghai City Committee of science and technology project (No.10160501700).

\section{REFERENCES}

[1] XI Peiqi, WU Miaofeng. Application of Synchronized Phasor Measurement Device in Far East $500 \mathrm{Kv}$ Substation[J]. East China Electric Power, 2014, 42(7) : 1480-1482.
[2] CHENG Yunfeng, ZHANG Xinran, LU Chao. Research progress of the application of wide area measurement technology in power system[J]. Power System Protection and Control, 2014, 42(4) : 145-153.

[3] DONG Qing, ZHAO Yuan, LIU Zhigang, et al. A Locating Method of Earth Faults in Large-scale Power Grid by Using Wide Area Measurement System[J]. Proceedings of the CSEE, 2013, 33(31) : 140146, S17.

[4] WU Xing, LIU Tianqi, LI Xingyuan, et al. Optimal Configuration of PMU Based on Data Compatibility of WAMS/SCADA and Improved FCM Clustering Algorithm[J]. Power System Technology, 2014, 38(3) : 756-761.

[5] SUN Qiuye, CHEN Huimin, YANG Jianong, et al. Analysis on Convergence of Newton-like Power Flow Algorithm[J]. 2014,34(13) : 2196-2200.

[6] AN Sicheng, WU Kehe, BI Tianshu, et al. Synchronization Algorithm for Real-Time Data Concurrent Access Applicale to WAMS[J]. Proceedings of the CSEE, 2014, 34(19) : 3226-3233.

[7] XU Yan, LU Bin, WANG Zengping. A Power Flow Transfer Identification Scheme Baesd on WAMS [J]. Proceedings of the CSEE, 2013, 33(28) : 154-160, S21.

[8] ZHAO Yuanyuan, CUI Yong, AI Qian. Dynamic Adjustment Schemes for Divisional Power Grid Structures Based on Phasor Measurement Unit[J], East China Electric Power, 2014, 47(5) : 0859-0864.

[9] CHEN Liang, BI Tianshu, LI Jinsong, et al. Dynamic State Estimator for Synchronous Machines Based on Cubature Kalman Filter[J]. Proceedings of the CSEE, 2014, 34(16) : 2706-2713. 